\title{
Multiple vaccinations, health, and recall bias within UK armed forces deployed to Iraq: cohort study
}

\author{
Dominic Murphy, research worker , Matthew Hotopf, professor of general hospital psychiatry, \\ Simon Wessely, professor of epidemiology and liaison psychiatry
}

King's Centre for Military Health Research, King's College London SE5 9RJ

Correspondence to: D Murphy dominic.murphy@iop.kcl.ac.uk

BMJ 2008;:1-4

doi:10.1136/bmj.a220

\section{ABSTRACT}

Objective To assess the relation between self reported number of vaccinations received and health, and between numbers of vaccinations recorded from individuals' medical records and health.

Design First phase of a cohort study.

Setting UK armed forces personnel.

Participants 4882 randomly selected military personnel deployed to Iraq since 2003 and a subset of 378 whose vaccination records were accessed.

Main outcome measures Psychological distress, fatigue, symptoms of post-traumatic stress disorder, health perception, and multiple physical symptoms.

Results Personnel who reported receiving two or more vaccinations on a single day were more likely to report symptoms of fatigue (adjusted risk ratio 1.17, 95\% confidence interval 1.05 to 1.30), show caseness according to the general health questionnaire $(1.31,1.13$ to 1.53$)$, and have multiple physical symptoms (1.32, 1.08 to 1.60$)$. These associations were no longer significant when number of vaccinations recorded in individuals' medical records was used as the independent variable.

Conclusions Multiple vaccinations given to personnel in the UK armed forces in preparation for deployment to Iraq are not associated with adverse health consequences when vaccinations are recorded objectively from medical records. Adverse health consequences associated with self reported multiple vaccinations could be explained by recall bias.

\section{INTRODUCTION}

Several studies have found an association between self reported multiple vaccinations in service personnel deployed to the $1991 \mathrm{Gulf}$ war and ill health in Gulf war veterans. $^{1-6}$ While multiple vaccinations were associated with the onset of symptoms, they were not a risk factor for the continuation of poor health. ${ }^{7}$ Researchers, however, did not have contemporaneous vaccination records. Other studies that did not find such an association $^{89}$ have led to concern over the validity of earlier findings. It is argued that the sample examined might not have been representative, that there could have been over-reporting of vaccinations, ${ }^{10}$ that other exposures could not be adequately controlled for, ${ }^{11}$ and that recall bias was responsible for the results. Retrospective recall of symptoms can be affected by recall bias. ${ }^{12}$

We examined the impact of receiving multiple vaccinations on health within two samples: one in which receipt of vaccinations was self reported and the other (a subset of the first) in which vaccinations were confirmed from individuals' medical records. This allowed us to observe the effects on health of receipt of multiple vaccinations and the influence of recall bias.

\section{METHODS}

\section{Sampling}

We conducted a cross sectional study of the UK armed forces from June 2004 to March 2006. Two groups of personnel randomly selected from UK armed forces were surveyed: the first had deployed to the 2003 Iraq war, and the second group had not. Details of sampling and methods of data collection are described elsewhere. $^{13}$

We restricted the current analyses to participants who had deployed either during the Iraq war or had subsequently deployed to Iraq. Data were collected through detailed questionnaires. Participants were asked "What was the maximum number of any vaccines that you received in one day in preparation for your deployment?" Examples of the vaccinations administered to service personnel include those against anthrax, tetanus, typhoid, and yellow fever. All such vaccines, with the exception of the anthrax vaccination, were administered routinely. The anthrax vaccination was offered under a separate programme that included information and written consent.

\section{Health measures}

Our outcome variables included a range of health measures: a 13 item fatigue scale,$^{14}$ a general health questionnaire (GHQ-12), ${ }^{15}$ a 53 item physical symptom checklist, ${ }^{2}$ self perception of health with a single item from the SF-36, ${ }^{16}$ and symptoms of post-traumatic stress disorder measured with a 17 item checklist (PCLC). ${ }^{17}$ Table 1 describes case definitions. Over $95 \%$ of participants gave us permission to access their medical records. 
Table 1| Case definitions according to follow-up health outcomes

\begin{tabular}{ll} 
Scale & \multicolumn{1}{c}{ Case definition } \\
Fatigue scale & Score of $\geq 4$ \\
\hline GHQ-12 & Score of $\geq 4$ \\
\hline Health perception & Rating health as "fair" or "poor" \\
\hline 53 item symptom checklist & $\geq 18$ (>90th centile) \\
\hline PTSC (PCL-C) & Score of $\geq 50$ \\
\hline
\end{tabular}

$\mathrm{GHQ}=$ general health questionnaire; $\mathrm{PTSC}=$ post-traumatic stress centre checklist.

Receipt of vaccinations taken from medical records

We randomly selected a subset of $10 \%$ of our sample to assess agreement between the number of self reported vaccinations received on a single day and what was recorded in their medical records. A member of the research team visited military medical centres, collected data on vaccination, and recorded the maximum number of vaccinations received on a single day before deployment from 31 July 2002 to 31 March 2006. To avoid missing data, we accessed deployment medical records as well as standard medical records.

\section{Analysis}

We used weighted $\kappa$ statistics to assess the level of agreement between self reported number of vaccinations received during one day and the number recorded within a participant's medical records. We used $\chi^{2}$ test for categorical data and Mann-Whitney U test for continuous data to identify sociodemographic differences between those whose records were checked and those in the full sample. Logistic binomial regression models were fitted to calculate risk ratios (with 95\% confidence intervals) between health outcomes and self reported receipt of multiple vaccinations on one day and health outcomes and receipt of multiple vaccinations on one day according to medical records. This analysis was repeated between self reported receipt and health in the subsample whose records had been accessed. Analyses were weighted according to sampling fractions and adjusted for service (navy, army, and air force), rank (officer or not), sex, age, medical fitness (a dichotomous marker that indicated whether fit to deploy or not, and enlistment status (regular or reserve). Analyses were conducted with Stata 9 (StataCorp, College Station, TX).

\section{RESULTS}

The participation rate was $61 \%(n=10272)$. Some 4882 participants had deployed either during the invasion of Iraq or on subsequent operations to Iraq and had answered the question pertaining to the maximum number of vaccinations received on one day. Of these, $14 \%$ were in the navy, $68 \%$ in the army, and $18 \%$ in the air force; $16 \%$ were officers; $8 \%$ were women; and $10 \%$ were in the reserves The median age was 32.2 years (interquartile range 26.4-38.2). An intensive follow-up study of non-responders found no significant differences in health between responders and non-responders. ${ }^{13} 18$

From our selected subsample we were able to access the records of 420 individuals. The medical records for 378 of these individuals recorded that they had received one or more vaccinations and form the basis of our analysis. Within this group, for 303 individuals we had both self reported and medical records vaccination data. For these 303 individuals we assessed the level of agreement between self reported receipt of multiple vaccinations received on one day and what was recorded in the medical records. The $\kappa$ score was 0.04 (95\% confidence interval -0.02 to 0.12$)$, indicating poor agreement. Table 2 shows the number of self reported vaccinations against the number recorded within medical records.

There were differences in sociodemographic variables between the sample whose records were checked and the full sample (table 3). Among individuals whose records were checked, more were in the army and nearly all were regular personnel compared with the full sample, in which $90 \%$ were regular personnel. Also, individuals whose records were checked were marginally younger. We investigated the relation between self reported receipt of no more than one vaccination or two or more vaccinations on one day and adverse health (table 4). After adjustment, we found significant associations between receipt of two or more vaccinations on one day and caseness for fatigue (odds ratio $1.17,95 \%$ confidence interval 1.05 to 1.30$)$, common mental disorder $(1.31,1.13$ to 1.53$)$, and multiple physical symptoms $(1.32,1.08$ to 1.60$)$.

We repeated the analysis using the number of vaccinations recorded from participants' medical records (table 4). Without exception, we found no health differences between individuals whose medical records indicated they had received no more than one and those who had received two or more vaccinations on a single day.

Table 4 also shows results of the analysis between health and self reported number of vaccinations restricted to those individuals whose records had also been checked. After adjustment, we found significant associations between receipt of two or more vaccinations and caseness for fatigue $(1.57,1.06$ to 2.33$)$ and common mental disorder $(1.89,1.08$ to 3.30$)$.

\section{DISCUSSION}

In this study of personnel deployed to Iraq we found that recall of the number of vaccinations received on a single day cannot be considered reliable. This is not the case for individual vaccinations-for example, self reported uptake of the anthrax vaccinations by UK and US military personnel is highly reliable. ${ }^{1920}$ Recall bias

Table 2| Number of self reported vaccines against number of vaccines recorded in medical records (for individuals who received one or more vaccinations)

\begin{tabular}{lcccc} 
& \multicolumn{4}{c}{ Medical records } \\
\cline { 2 - 5 } Self report & $\mathbf{1}$ & 2 & 3 & $\geq 4$ \\
1 & 68 & 38 & 9 & 4 \\
\hline 2 & 70 & 26 & 13 & 1 \\
\hline 3 & 24 & 15 & 14 & 0 \\
\hline$\geq 4$ & 11 & 6 & 1 & 3 \\
\hline
\end{tabular}


Table 3 Demographic characteristics between those whose medical records were checked and those whose records were not checked. Figures are numbers (percentages*) of participants unless stated otherwise

\begin{tabular}{|c|c|c|c|}
\hline & $\begin{array}{c}\text { Self reported } \\
\text { vaccination }(n=4882)\end{array}$ & $\begin{array}{l}\text { Medical records checked } \\
\qquad(\mathrm{n}=420)\end{array}$ & P value $†$ \\
\hline \multicolumn{4}{|l|}{ Service: } \\
\hline Navy & $669(14)$ & $44(11)$ & \multirow{3}{*}{$<0.001$} \\
\hline Army & $3376(68)$ & $212(50)$ & \\
\hline Air force & $837(18)$ & 164 (39) & \\
\hline \multicolumn{4}{|l|}{ Rank: } \\
\hline Officer & $825(16)$ & $57(13)$ & \multirow{2}{*}{0.126} \\
\hline Other ranks & $4057(84)$ & $363(87)$ & \\
\hline \multicolumn{4}{|l|}{ Sex: } \\
\hline Male & $4436(92)$ & $388(92)$ & \multirow{2}{*}{0.579} \\
\hline Female & $446(8)$ & $32(8)$ & \\
\hline \multicolumn{4}{|l|}{ Enlistment status: } \\
\hline Regular & $3981(90)$ & $419(100)$ & \multirow{2}{*}{$<0.001$} \\
\hline Reservist & $901(10)$ & $1(0)$ & \\
\hline Mean age $(95 \% \mathrm{Cl})$ & 32.9 (32.7 to 33.14$)$ & 31.8 (31.1 to 32.5$)$ & 0.005 \\
\hline
\end{tabular}

seems to mediate an association between self reported uptake of multiple vaccinations and experiencing poorer health. Such associations were no longer significant, however, when we repeated the analyses using receipt of vaccinations recorded from an individual's medical records rather than self report. In view of these findings, we conclude that there is no evidence that receiving multiple vaccinations has resulted in adverse health for UK service personnel deployed to Iraq since 2003.
What do these findings tell us about multiple vaccines and earlier studies on illness after the 1991 Gulf war? Important differences exist in the administration of medical countermeasures between the two wars. In general, vaccinations administered to UK service personnel deployed to Iraq since 2003 were administered before their deployment; this was not the case during the 1991 Gulf war when many personnel received vaccinations while on deployment. Pertussis was not offered to service personnel in 2003 but was used as an adjuvant for the anthrax vaccination in 1991 and was proposed as a possible cause of symptoms. ${ }^{21}$ The total number of vaccines reportedly received in UK Gulf war veterans was considerably higher than in 2003, and most of the studies were not limited to total vaccines received on a single day but before and during deployment. In these earlier studies many participants reported receiving six or more vaccines, and the association was concentrated in those in this extreme group. Furthermore, while there was a health effect to be explained after the 1991 Gulf war, there has not been evidence of a new "Iraq war syndrome."1322

\section{Strengths and weaknesses}

One strength of this study was that we were able to analyse data from both self reported measures and medical records about the number of vaccinations received. This allowed us to ascertain both the effects of vaccinations on health and the possible impact of recall bias. Our sample was randomly selected and representative of the UK armed forces.

There were sociodemographic differences between the full sample and the subset of people whose medical

Table 4 | Health comparisons between individuals according number of vaccinations received on single day and self reported vaccination, vaccination in medical records, and subsample of self reports with medical records also checked. Figures are numbers (percentage ${ }^{\star}$ ) of participants

Received no more than 1 vaccination on 1 day

Self reported vaccination

\begin{tabular}{|c|c|c|c|c|}
\hline Fatigue case & $366 / 1266(29)$ & $1036 / 2893(35)$ & $1.23(1.11$ to 1.35$)$ & $1.17(1.05$ to 1.30$)$ \\
\hline Common mental disorder (GHQ-12) & $199 / 1272(16)$ & $635 / 2901(21)$ & 1.37 (1.18 to 1.58$)$ & 1.31 (1.13 to 1.53$)$ \\
\hline Multiple physical symptoms & $125 / 1289(10)$ & 406/2924 (14) & $1.41(1.17$ to 1.71$)$ & $1.32(1.08$ to 1.60$)$ \\
\hline Health perception & $134 / 1277(10)$ & $359 / 2914(12)$ & $1.13(0.94$ to 1.37$)$ & $1.02(0.84$ to 1.24$)$ \\
\hline PTSD (PCL-C) & $43 / 1265(3)$ & $130 / 2893(4)$ & $1.23(0.87$ to 1.73$)$ & $0.98(0.69$ to 1.39$)$ \\
\hline \multicolumn{5}{|l|}{ Medical records of vaccination } \\
\hline Fatigue case & $66 / 216(31)$ & 45/158 (29) & 0.94 (0.68 to 1.29$)$ & $0.92(0.66$ to 1.28$)$ \\
\hline Common mental disorder (GHQ-12) & 49/217 (23) & 24/159 (15) & $0.67(0.43$ to 1.04$)$ & $0.73(0.47$ to 1.14$)$ \\
\hline Multiple physical symptoms & $21 / 218(10)$ & $15 / 160(9)$ & $0.98(0.52$ to 1.84$)$ & 1.07 (0.58 to 1.97$)$ \\
\hline Health perception & 28/216 (13) & $10 / 159(6)$ & $0.49(0.24$ to 0.97$)$ & $0.54(0.27$ to 1.08$)$ \\
\hline PTSD (PCL-C) & $11 / 214(5)$ & $6 / 158(4)$ & 0.74 (0.28 to 1.96$)$ & $0.81(0.31$ to 2.15$)$ \\
\hline \multicolumn{5}{|l|}{ Self report and medical records } \\
\hline Fatigue case & $26 / 118(22)$ & $63 / 181(35)$ & 1.58 (1.07 to 2.35$)$ & 1.57 (1.06 to 2.33$)$ \\
\hline Common mental disorder (GHQ-12) & $14 / 118(12)$ & $41 / 183(22)$ & 1.89 (1.07 to 3.32) & 1.89 (1.08 to 3.30$)$ \\
\hline Multiple physical symptoms & $7 / 119(6)$ & 19/184 (10) & $1.76(0.70$ to 4.06$)$ & $1.81(0.79$ to 4.15$)$ \\
\hline Health perception & 9/117 (8) & $21 / 183(12)$ & $1.50(0.71$ to 3.16$)$ & $1.46(0.69$ to 3.13$)$ \\
\hline PTSD (PCL-C) & $3 / 116(3)$ & $8 / 182(4)$ & $1.70(0.46$ to 6.31$)$ & $1.60(0.44$ to 5.55$)$ \\
\hline
\end{tabular}

$\mathrm{GHQ}=$ general health questionnaire; $\mathrm{PTSC}=$ post-traumatic stress checklist.

*Percentages adjusted to take account of sampling fractions.

†Adjusted for age, sex, service, rank, fitness to deploy, and regular/reservist status. 


\section{WHAT IS ALREADY KNOWN ON THIS TOPIC}

Several studies have implicated multiple vaccinations as a risk factor for the excess ill health observed in Gulf war veterans

Previous studies have relied on retrospective self report of vaccination

\section{WHAT THIS STUDY ADDS}

Although self reported multiple vaccines were associated with illness, there was no such association when multiple vaccinations were ascertained from contemporaneous medical records

Earlier associations between self reported receipt of multiple vaccinations and illness were probably caused by recall bias
Competing interests: SW is honorary civilian consultant adviser to the British army.

Ethical approval: Ministry of Defence (Navy) personnel research ethics committee and the King's College Hospital local research ethics committee.

Provenance and peer review: Not commissioned; externally peer reviewed.

1 Cherry N, Creed F, Silman A, Dunn G, Baxter D, Smedley J, et al. Health and exposures of United Kingdom Gulf war veterans. Part II: the relation of health to exposure. Occup Environ Med 2001;58:299-306.

2 Unwin C, Blatchley N, Coker W, Ferry S, Hotopf M, Hull L, et al. Health of UK servicemen who served in Persian Gulf war. Lancet 1999;353:169-78.

3 Wolfe J, Proctor SP, Erickson DJ, Hu H. Risk factors for multisymptom illness in US Army veterans of the Gulf war. / Occup Environ Med 2002;44:271-81.

records were accessed. In particular, the medical records that were checked were almost exclusively those of regular personnel. We have previously found that reservists were at increased risk of ill health after deployment to Iraq, ${ }^{13}$ and we adjusted our current analyses for regular or reserve status. Finally, we recognise the self reported measure of multiple vaccinations used in this paper was crude (one question), and data were collected between two and three years after participants had received vaccinations. This might mean that individuals' responses about receipt of multiple vaccinations were more prone to recall bias than one might normally expect. While this might limit our findings that used self reported measures of vaccination uptake, data collected from medical records would be unaffected.

Evidence from Gulf war veterans indicates that recall of exposures was associated with current rating of health. Reporting new exposures was associated with a worsening of health. ${ }^{23}$ Within Gulf war veterans most exposures were associated with most outcomes, which points to evidence of recall bias. ${ }^{24}$

\section{Conclusions}

Receipt of multiple vaccinations in UK armed forces personnel before the 2003 Iraq war has not resulted in adverse health. Recall bias was evident with self reported measures of receipt of vaccinations. It is difficult to quantify the extent to which similar processes might have accounted for the reported associations between self reported multiple vaccinations and illness after the 1991 Gulf war.

We thank the UK Ministry of Defence for their cooperation; in particular we thank the Defence Medical Services Department, the Defence Analytical Services Agency, the Armed Forces Personnel Administration Agency, and the Veteran's Policy Unit.

Contributors: DM was the lead author in writing the paper and participated in the conduct of the research and analysis. MH was principal investigator sought funding, and participated in planning, supervision of data collection, writing of the paper, and commented on the analysis and writing. SW was principal investigator, sought funding, led the planning of the study and supervision of data collection, and commented on the analysis and writing of this paper. DM, MH, and SW are guarantors. Funding: UK Ministry of Defence. The work was independent of the funders but a copy of the paper was sent to them. The Defence Analytical Services Agency provided the sampling frames of the armed forces. The funders did not participate in data collection, data processing, data analysis, or interpretation of findings. MH and SW are funded by NIHR Biomedical Research Centre for Mental Health, South London and Maudsley NHS Foundation Trust, and Institute of Psychiatry, King's College London.
4 Steele L. Prevalence and patterns of Gulf war illness in Kansas veterans: association of symptoms with characteristics of person, place, and time of military service. Am J Epidemiol 2000;152:992-1002.

5 Kelsall HL, Sim MR, Forbes AB, Glass DC, McKenzie DP, Ikin JF, et al. Symptoms and medical conditions in Australian veterans of the 1991 Gulf war: relation to immunisations and other Gulf war exposures. Occup Environ Med 2004;61:1006-13.

6 Hotopf M, David A, Hull L, Ismail K, Unwin C, Wessely S. Role of vaccinations as risk factors for ill health in veterans of the Gulf war: cross sectional study. BMJ 2000;320:1363-7.

7 Hotopf M, David A, Hull L, Nikalaou V, Unwin C, Wessely S. Risk factors for continued illness among Gulf warveterans: a cohort study. Psychol Med 2004;34:747-54.

8 Macfarlane GJ, Biggs AM, Maconochie N, Hotopf M, Doyle P, Lunt M. Incidence of cancer among UK Gulf war veterans: cohort study. $B M J$ 2003;327:1373.

9 Payne DC, Aranas A, McNeil MM, Duderstadt S, Rose J. Concurrent vaccinations and US military hospitalizations. Ann Epidemiol 2007;17:697-703.

10 McCauley LA, Joos SK, Spencer PS, Lasarev M, Shuell T. Strategies to assess validity of self-reported exposures during the Persian Gulfwar. Portland Environmental Hazards Research Center. Environ Res 1999;81:195-205.

11 Shaheen S. Shots in the desert and Gulf war syndrome. Evidence that multiple vaccinations during deployment are to blame is inconclusive. $B M J$ 2000;320:1351-2.

12 Koren G, Maltepe C, NaviozY, Wolpin J. Recall bias of the symptoms of nausea and vomiting of pregnancy. Am J Obstet Gynecol 2004;190:485-8.

13 Hotopf M, Hull L, Fear NT, Browne T, Horn O, Iversen A, et al. The health of UK military personnel who deployed to the 2003 Iraq war: a cohort study. Lancet 2006;367:1731-41.

14 Chalder T, Berelowitz G, Pawlikowska T, Watts L, Wessely S, Wright D, et al. Development of a fatigue scale. J Psychosom Res 1993;37:147-53.

15 Goldberg D, William P. A users' guide to the general health questionnaire. Windsor: NFER-Nelson, 1998.

16 Ware JE Jr, Sherbourne CD. The MOS 36-item short-form health survey (SF-36). I. Conceptual framework and item selection. Med Care 1992;30:473-83.

17 Blanchard EB, Jones-Alexander J, Buckley TC, Forneris CA. Psychometric properties of the PTSD checklist (PCL). Behav Res The 1996;34:669-73.

18 Tate AR, Jones M, Hull L, Murphy D, Hotopf M, Rona R, et al. How many mailouts: could attempts to increase the response rate in the Iraq wa cohort study be counter-productive? BMC Med Res Methodol 2007;7:51.

19 Smith B, Leard CA, Smith TC, Reed RJ, Ryan MA, Millennium Cohort Study Team. Anthrax vaccination in the millennium cohort: validation and measures of health. Am / Prev Med 2007;32:347-53.

20 Murphy D, Hull L, Horn O, Jones M, Marteau T, Hotopf M, et al. Anthrax vaccination in a military population before the war in Iraq: side effects and informed choice. Vaccine 2007;25:7641-8.

21 Rook GA, Zumla A. Gulf war syndrome: is it due to a systemic shift in cytokine balance towards a Th2 profile? Lancet 1997;349:1831-3.

22 Horn O, Hull L, Jones M, Murphy D, Browne T, Fear NT, et al. Is there an Iraq war syndrome? Comparison of the health of UK service personnel after the Gulf and Iraq wars. Lancet 2006;367:1742-6.

23 Wessely S, Unwin C, Hotopf M, Hull L, Ismail K, Nicolaou V, et al. Stability of recall of military hazards over time: evidence from the Persian Gulf war of 1991. Br J Psychiatry 2003;183:314-22.

24 Hotopf M, Wessely S. Can epidemiology clear the fog of war? Lessons from the 1990-91 Gulf war. Int I Epidemiol 2005;34:791-800.
Accepted: 5 May 2008 